\title{
A Research on the Academic Improvement Effects of Extracurricular Mathematics Tutoring for Chinese High School Students
}

\author{
Lecun $\mathrm{Liu}^{1}$ \\ ${ }^{1}$ School of Teacher Education, Nanjing Normal University, Nanjing 210023, China \\ Correspondence: Lecun Liu, Nanjing Normal University, Xian Lin Campus, No.1 Wenyuan Road, Qixia District, \\ Nanjing, Jiangsu, China. E-mail: runzi1998@163.com
}

Received: January 25, 2022

Accepted: February 24, 2022

Online Published: February 27, 2022

doi:10.20849/aes.v7i1.1017

URL: https://doi.org/10.20849/aes.v7i1.1017

\begin{abstract}
To examine the academic enhancement effects of extracurricular tutoring in mathematics at the high school level, 439 questionnaires were distributed in the second year of senior high school to collect information on the number of participants in different types of tutoring and the grade level mathematics scores before and after tutoring, and the data obtained were analyzed for differences using SPSS software. The results showed that (1) extracurricular tutoring in mathematics for high school students can improve students' academic performance, but the improvement effects of different types of extracurricular tutoring have significant differences. (2) Among students of different levels, the degree of improvement in the group of mathematics students with difficulties was significantly higher than that in the group of intermediate and superior students; the degree of improvement within the group of intermediate students was seriously polarized. Therefore, the academic improvement effect of extracurricular tutoring in mathematics varies depending on the type of tutoring, students with learning difficulties in mathematics should consider choosing appropriate extracurricular tutoring in mathematics, and mathematics teachers should strengthen personalized guidance for students.
\end{abstract}

Keywords: extra-curricular mathematics tutoring, academic effectiveness, high school students, achievement improvement

\section{Introduction}

In July 2021, the General Office of the State Council of China issued a major education policy, "Opinions on Further Reducing the Burden of Homework and Extracurricular Training for Students in Compulsory Education", which opened a new phase in the history of "double reduction". This policy has led to a reduction in the amount of homework for students in compulsory education, fewer exams, and the closure and cancellation of extracurricular coaching institutions. However, it is worth noting that in the above-mentioned document, the "overall reduction in the total amount of homework and significant reduction in the pressure of examinations" is mainly for the compulsory education stage, that is, elementary school (6 years) and junior high school (3 years). For high school, when facing the pressure of college entrance exams, many students and parents hope to improve their grades through extracurricular tutoring. In this context, this paper examines how effective extracurricular tutoring in mathematics for high school students actually is in terms of academic improvement.

The number of studies on extracurricular tutoring for high school students has been on the rise in recent years, and extracurricular tutoring has become a hot issue in society. At present, most studies have studied the current situation of extracurricular tutoring from the overall perspective (Xia Anqi, 2019), mainly including: the scale of tutoring, the reasons for tutoring, the content of tutoring, the way of tutoring, the intensity of tutoring, and the distribution of teachers, etc. There is no quantitative research on the effect of tutoring. Although studies have given attention to it, the conclusions of the studies are not accurate. For example, one study used a questionnaire to collect the degree of improvement as perceived by students themselves and the degree of improvement as perceived by parents (Pei Changgen et al, 2019), and the results showed that most students perceived significant improvement, while most parents did not. The academic enhancement effect, or grade improvement effect, is one of the most important effects of extracurricular tutoring (Wang Guoqing, 2016). Therefore, in this paper, we want to study the effect of extracurricular tutoring from an empirical perspective, using specific final exam scores to measure the degree of academic improvement of students over the course of a semester, using the grade difference as the dependent variable. 
Recent studies have shown that extracurricular tutoring in mathematics at the compulsory level can enhance students' interest in learning, motivation, and knowledge system construction (Liu Shanshan \& Yang Xiangdong, 2015). However, there is no research on the type, that is, it is not specified which type of extracurricular tutoring produces the effect and whether there is a difference between the effects. In addition, from the perspective of students at different levels, some studies have shown that English extracurricular tutoring varies widely for different types of students and that not much change occurs for students who are struggling. Therefore, this paper uses the type of tutoring classes and different levels of students as the independent variables to focus on the differences in academic improvement effects of different types of extracurricular tutoring and different levels of students.

Since mathematics in high school is a critical period for the development of formal operations, abstract thinking and logical thinking have reached a new level compared to elementary school, so this study is based on the high school level and focuses on extracurricular tutoring in mathematics to fully reflect the characteristics of the subject.

To sum up, this paper takes mathematics as an example to investigate whether extracurricular tutoring in mathematics for high school students can improve students' academic performance in mathematics. Based on this, the following research questions are proposed.

1) From within extracurricular tutoring, how do the academic enhancement effects of different types of extracurricular tutoring in mathematics differ?

2) From the students' perspective, what are the differences in the academic enhancement effects obtained by students of different mathematics levels who participated in tutoring?

\section{Concept Definition}

Private Supplementary Tutoring (PST), which some people call "shadow education", refers to the content of extracurricular tutoring, which often follows the content of in-school learning like a shadow (Shi Ruoyu, 2015). Extracurricular tutoring, also known as extracurricular tutoring classes, is a kind of educational tutoring institution that has emerged in response to students' problems in school learning and is given after-school tutoring (Tang Xinrong, 2015).

Extra-curricular tutoring in mathematics, as referred to in this study, refers to tutorial education aimed at improving academic performance in mathematics mainly paid for by the student's family outside of normal schooling (Zhou Zhicheng, 2015), with mathematics teaching courses as the main component. It contains two definitions. The first is "tutorial". The tutoring that is the focus of this paper is only mathematics tutoring. The second is "profitability" (Tang P, 2015). The actual tutors or tutoring institutions in this paper provide tutoring for profit, not including free tutoring provided by schools, and not including school-based tutoring activities arranged by schools for the whole year or the whole class.

Academic improvement effect, i.e., the degree of improvement in math scores. The effect of extracurricular tutoring has various aspects (Jiang Yazang, 2014), such as improved motivation, changed study habits, improved thinking skills, improved subjective motivation, and complete knowledge structure. In this paper, we study one of the most intuitive effects, i.e., whether students' mathematics scores improve after attending extracurricular tutoring.

\section{Research Program}

In this study, quantitative analysis was used to collect students' tutoring through questionnaires in order to group students and do ANOVA (difference test) on the changes of mathematics achievement of different tutoring types and different levels of students to explore the academic improvement effect of extracurricular tutoring in mathematics in a more systematic way.

\subsection{Questionnaire Design}

Through the questionnaire (see Appendix for details), the following three types of data need to be obtained: students' basic information (name, student number, class), whether they have attended tutoring classes, and what type of tutoring they attended.

The first question, basic student information, was filled in by real name to facilitate finding students' performance before and after extracurricular tutoring.

For the second question, referring to previous studies, the change in grades can be seen first when the tutoring period is 1 semester, so one semester is taken as the investigation period. This study investigated the effect of tutoring in the first semester of sophomore year, so the variable was set as whether the current students in the 
second semester of sophomore year had participated in tutoring in the first semester of sophomore year. If they did, it was recorded as 1 , otherwise it was recorded as 0 .

For the third question, referring to previous studies (Fu Hongxiu, 2014), extracurricular tutoring in mathematics was divided into five categories (online tutoring class instruction, offline tutoring classes, extracurricular classes by famous teachers, one-on-one tutoring institutions, and tutoring by school students), and the options were listed in the questionnaire, hoping that the survey would reveal the students' choices.

\subsection{Collecting Data}

A questionnaire was administered to sophomore students in a high school in Nanjing. This questionnaire was administered as a collective class practical test, with three graduate students as the main testers, and distributed and collected with the help of class teachers or class leaders. Eight classes were randomly selected and a total of 439 questionnaires were distributed for extracurricular math tutoring, and 416 questionnaires were collected, with a recovery rate of $98.4 \%$. After sorting the questionnaires and deleting those questionnaires that were not filled out by individuals, or those that were not answered in large areas or were answered randomly, 367 valid questionnaires were obtained (the questionnaire efficiency rate reached $88.1 \%$ ).

Students' mathematics scores: With the consent of the school director and the sample students, the students' names, school numbers, and classes were used to obtain the students' mathematics scores in the final examinations of the first semester of senior high school and the first semester of sophomore high school, using real names.

\subsection{Grouping and Data Processing}

(1) Students who participated in the tutoring were recorded as the experimental group and those who did not participate in the tutoring were recorded as the control group, and the changes in their performance would be studied. The data in the questionnaire were organized into the following table.

Table 1. The number and percentage of the experimental and control groups

\begin{tabular}{cccc}
\hline Group & Types of coaching & $\begin{array}{c}\text { Number of } \\
\text { people }\end{array}$ & Proportion \\
\hline Experimental group (256) & Online Coaching & 58 & $15.8 \%$ \\
& Off-line coaching & 97 & $26.4 \%$ \\
& Classes by Master Teachers & 89 & $24.2 \%$ \\
& One-on-one in a tutoring & 41 & $11.1 \%$ \\
& institution & & $15.2 \%$ \\
Control group (111) & College Student Tutor & 59 & $30.3 \%$ \\
& Without coaching & 111 & $100 \%$ \\
\hline
\end{tabular}

According to the questionnaire survey, 256 students participated in extracurricular tutoring in mathematics in the first semester of their sophomore year, accounting for $69.7 \%$ of the survey population. It can be seen that more than half of the students participated in extracurricular mathematics tutoring, indicating that it is a relatively common phenomenon for high school students to participate in extracurricular mathematics tutoring. Among them, offline tutoring and teacher-run classes accounted for $26.4 \%$ and $24.3 \%$ respectively.

(2) Grouping of students with different mathematics levels. The 256 students in the experimental group were divided into three classes of students according to their final exam scores in the second semester of senior high school. The students with the top $27 \%$ of the overall scores were divided into the group of students with high academic achievement, the students with the bottom $27 \%$ were divided into the group of students with low academic achievement, and the rest of the students were in the group of intermediate students. The results of the classification are shown in the following table. 
Table 2. The number and percentage of students in the three groups with different levels

\begin{tabular}{lcc}
\hline Group & Number of people & Proportion \\
\hline High academic achievement & 31 & $12.1 \%$ \\
Intermediate students & 142 & $55.4 \%$ \\
Low academic achievement & 82 & $32.0 \%$ \\
\hline
\end{tabular}

The level of mathematics achievement has a great influence on whether students are willing to participate in extracurricular tutoring in mathematics (Shen Lei, 2014), and the data show that the participation of intermediate students in tutoring is particularly active, accounting for $55.4 \%$, almost half of the experimental group, which has the foundation of mathematics, but the situation of not being able to fully understand the knowledge points at school requires time spent outside of class for tutoring. The percentage of academically gifted students participating in mathematics tutoring is lower, probably because they have developed good mathematical habits and have the ability to learn on their own, so the number of tutoring is lower.

(3) Data organization. Considering that the two exams are non-standardized and individual schools may cause biased estimates of student performance due to differences in test difficulty, the raw scores should not be directly used for analysis (Wen Yanjing, 2013). In this study, we refer to the treatment of similar studies and standardize math scores by class with the standardized formula: standardized score $=$ (raw score - lowest class score)/(highest class score - lowest class score) (He Xiaoqing, 2013). The difference between the two standardized grades was used as the grade change (later referred to as the academic progress value). An empirical approach was used to analyze the effect of extracurricular tutoring on high school mathematics performance by tracking students' mathematics performance.

In summary, the type of extracurricular tutoring and students' mathematics level were used as independent variables and the change in achievement was used as the dependent variable, and the SPSS 25.0 software was used to do an ANOVA on the academic progress values for each group.

\section{Results}

(1) Analysis of the differences in academic progress values between the high school extracurricular mathematics tutoring group and the control group.

The results of the ANOVA on the changes in standardized scores between the extracurricular mathematics tutoring group and the control group during one semester are shown in Table 3. (ANOVA homogeneity of variance test was passed)

Table 3. ANOVA of the changes in standard scores of the experimental and control groups $(\mathrm{M} \pm \mathrm{SD})$

\begin{tabular}{lccc}
\hline Group & $\begin{array}{c}\text { Mean and standard } \\
\text { deviation }(\mathrm{M} \pm \mathrm{SD})\end{array}$ & $\begin{array}{c}\text { F(Differences with } \\
\text { the control group) }\end{array}$ & $\mathrm{p}$ \\
\hline Online Coaching & $0.179 \pm 0.038$ & 0.8 & 0.065 \\
Off-line coaching & $0.189 \pm 0.021$ & 19.25 & $0.018^{*}$ \\
Classes by Master Teachers & $0.188 \pm 0.073$ & 13.00 & $0.023^{*}$ \\
One-on-one in institution & $0.186 \pm 0.043$ & 8.31 & $0.027^{*}$ \\
College Student Tutor & $0.183 \pm 0.091$ & 6.00 & 0.057 \\
Total experimental groups & $0.187 \pm 0.065$ & 11 & $0.020^{*}$ \\
Control group & $0.180 \pm 0.016$ & .00 & 1.000 \\
\hline
\end{tabular}

Note: $* \mathrm{p}<0.05$

Within the experimental group, only "online tutoring" and "college tutoring" showed significant differences from the control group, $\mathrm{p}<0.05$. The rest of the types were significantly different from the control group, and because the data were standardized, the numerical improvement was not significant, but they all passed the significance test. Thus, the results indicate that extracurricular tutoring in mathematics for high school students has some academic improvement effect, but the difference between the different types of tutoring is significant. 
The mean values of the changes in achievement for each type of tutoring group and the control group (who did not participate in tutoring) are shown in Figure 1.

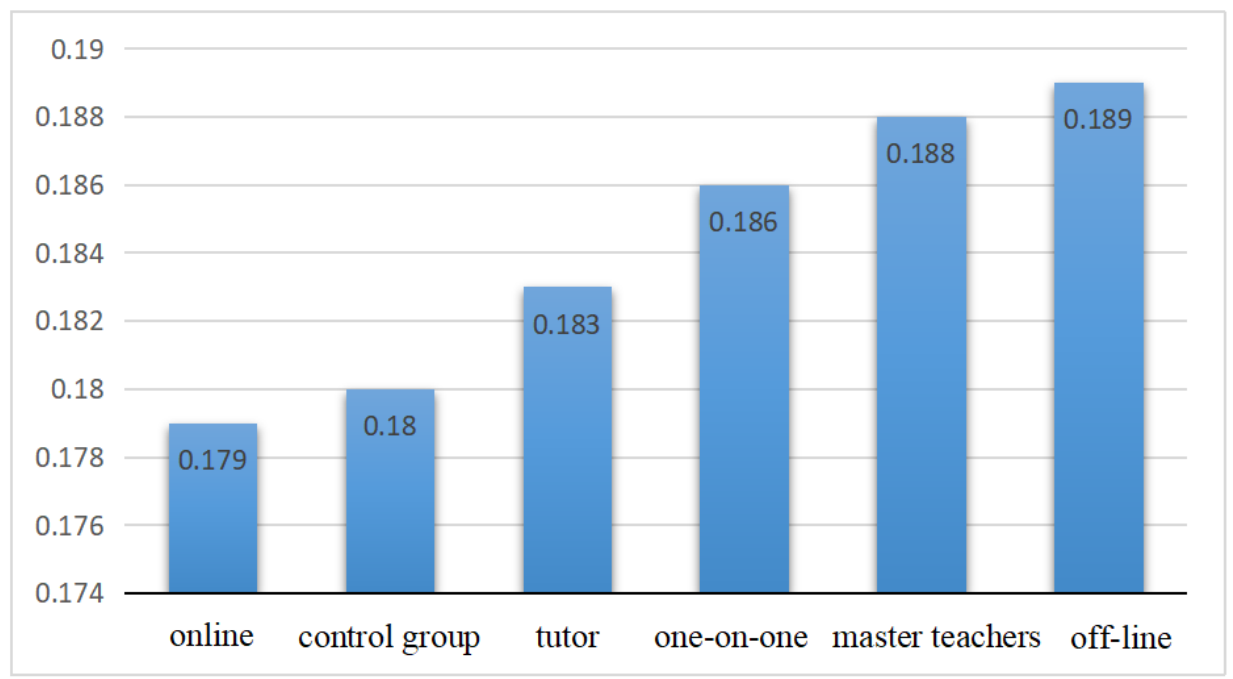

Figure 1. Histogram of the change in performance of the experimental group and the control group

Looking at the standard scores of online tutoring, after a semester of extracurricular tutoring, students' performance did not improve but showed a decreasing trend: the standard scores of mathematics at the end of the second year of high school were 0.01 lower than the standard scores at the end of the second year of high school, and did not pass the significance test, i.e., semester tutoring lowered students' standard scores in mathematics. Thus, the relatively low improvement effect of online tutoring reflects the fact that there are indeed problems with online instruction, which is consistent with the view that "the effect of online instruction is limited during the epidemic" found in previous studies (Sun Huiming, 2013). The reason for this is that the 2020 epidemic gave rise to a large number of online educational tutoring institutions, which did solve some problems at the time, but the teachers' qualifications were mixed and the quality of teaching was worrisome, and some of the problems of online teaching could not be avoided by online tutoring. Home tutoring although from the mean said 0.03 more than the control group, but the variance test shows

(2) Analysis of differences in academic progress values for students at different levels of mathematics

The statistical results and SPSS ANOVAs of the academic progress values of the students at the three different levels within one semester are shown in Tables 4 and 5.

Table 4. Academic progress values for students at three different levels $(\mathrm{M} \pm \mathrm{SD})$

\begin{tabular}{lc}
\hline \multicolumn{1}{c}{ Group } & $\begin{array}{c}\text { Mean and standard deviation of progress values } \\
(\mathrm{M} \pm \mathrm{SD})\end{array}$ \\
\hline High academic achievement & $0.181 \pm 0.015$ \\
Intermediate students & $0.184 \pm 0.052$ \\
Low academic achievement & $0.193 \pm 0.031$ \\
\hline
\end{tabular}

The result of the homogeneity of variance test shows that $p$ is 1 , the variance of the sample is the same and the analysis of variance can be continued. 
Table 5. Multiple comparisons of the academic progress values of students at three different levels

\begin{tabular}{clcc}
\hline Group & \multicolumn{1}{c}{ Group } & Significance & $\begin{array}{c}\text { Difference of mean } \\
\text { value (Significance } \\
\text { level is 0.05) }\end{array}$ \\
\hline High academic & Intermediate students & 0.010 & $-0.003^{*}$ \\
achievement & Low academic achievement & 0.000 & $-0.012^{*}$ \\
Intermediate students & High academic achievement & 0.010 & $0.003^{*}$ \\
& Low academic achievement & 0.000 & $-0.009^{*}$ \\
Low academic & High academic achievement & 0.000 & $0.012^{*}$ \\
achievement & Intermediate students & 0.000 & $0.009^{*}$ \\
\hline
\end{tabular}

The results of the multiple comparisons showed that there was a significant difference between the progress values of the struggling students and the intermediate and superior students $(\mathrm{p}=0<0.01)$, and between the intermediate and superior students, but the progress of the struggling students was still greater than the first two groups in terms of the average progress values $(0.012$ more than the superior students and 0.009 more than the intermediate students). Analysis of the reasons: there are a number of students who have difficulties in learning mathematics, and large classes (an average of more than 50 students in a class) result in teachers not being able to care about everyone. So students who face problems such as not adapting to the pace of learning, not being able to understand the lesson, and thinking more than on, may consider choosing appropriate extracurricular tutoring. Tutoring or one-on-one tutoring can go some way to solving the "problem".

To further investigate the distribution of achievement within each group, the box plots of academic progress values within the three groups of students were made using SPSS software as follows.

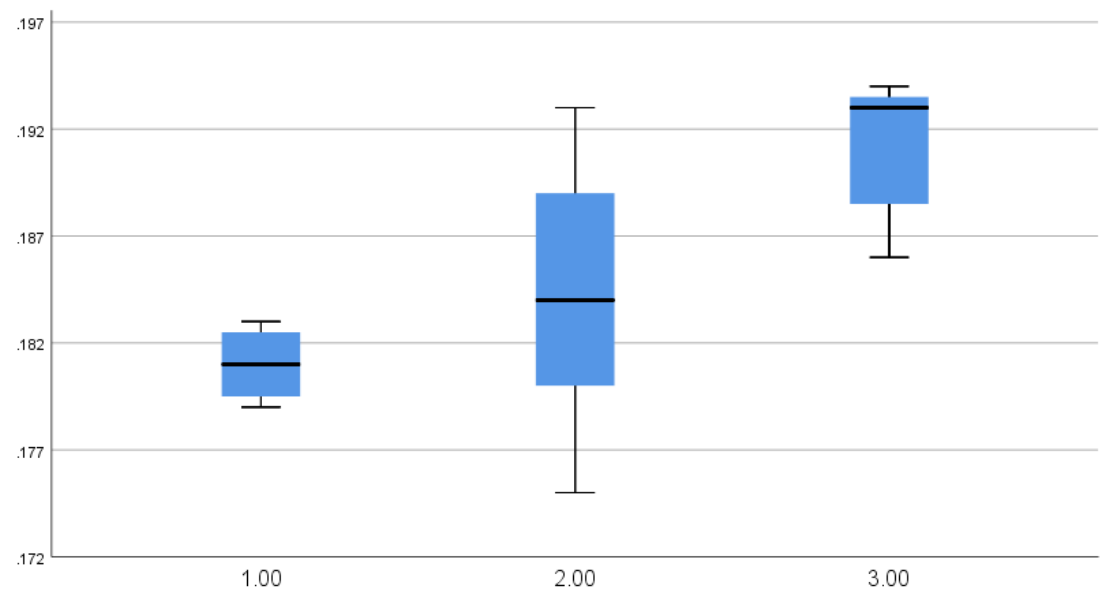

Figure 2. Box plots of academic progress values within the three groups of students

Among the students of different levels, the group of mathematics students who were struggling had a significantly higher level of progress than the group of intermediate and superior students; the group of intermediate students had the most significant intra-group differences in the level of progress. That is, there was a greater degree of polarization in the degree of progress among students. There were some students who made little or no progress.

\section{Discussion}

The results of the study indicate that extracurricular tutoring in mathematics has a significant academic improvement effect on poor high school mathematics students, which is consistent with existing findings. In terms of the type of extracurricular tutoring, this study found for the first time that online tutoring was not significant in terms of performance improvement, and the mean scores were even lower than those of the self-study students. It has been preliminarily revealed that there are some shortcomings in online instruction, and 
the findings further confirm that the quality of online instruction is lower than offline.

The time selected for this study was narrowly taught, and only the first semester of the sophomore year was chosen as an example. If there is sufficient time, a comparison of the entire year can be done to further investigate which year of the three years has the most significant academic improvement. Some scholars have studied tutoring in the high school segment from the perspective of class time (Ke Shanliang, 2012), and whether the effects of tutoring differed across time periods. Whereas this study only examined tutoring during school attendance, further research could be conducted to examine how the academic improvement effect differs between vacation tutoring and mid-semester tutoring.

A follow-up case study could be conducted to interview and observe students with significant and insignificant academic improvement, record changes before and after students' participation in tutoring, compare the factors and aspects that produced differences in their effects, and investigate the reasons for the improvement. An experimental study could also be conducted to extend these lessons from the extracurricular tutoring classes to school mathematics education, with the struggling students receiving the new education as the experimental group and the struggling students in regular daily instruction as the control group, to investigate whether the "tutoring" style of the new exercise education leads to academic improvement.

\section{Conclusions and Recommendations}

It was found that extracurricular tutoring in mathematics for high school students could improve students' academic performance, but the improvement effect of different types of extracurricular tutoring had significant differences; among them, online tutoring was not as effective as self-study, and online tutoring and master tutoring had the most significant effect on academic improvement. Among the students of different levels, the progress of the group of mathematics students with difficulty was significantly higher than that of the group of intermediate and superior students; the progress of the group of intermediate students was seriously polarized, and some students did useless work.

Therefore, extra-curricular mathematics tutoring should be viewed objectively as a "shortcut" for some students to make up for their shortcomings (Wang Du, 2009). For example, mathematics teachers are responsible for guiding or advising students on their choice of extracurricular tutoring, specifically by guiding students to identify their own gaps and weaknesses and encouraging them to study on their own or to choose appropriate extracurricular tutoring so that they can do less useless work. School mathematics education should follow the trend of the times. In the context of large class sizes, mathematics exercise classes or tutorials can add personalized tutorial content, tiered review or specific exercises for consolidation for students at different levels (Bai Hongliang \& Liu Jianqing, 2005). In order to reduce students' class load during the school year, parents are advised to choose to enroll during the holidays rather than in the middle of the semester.

\section{References}

Bai, H.-L., \& Liu, J.-Q. (2005). Research and practice on the effectiveness of tutoring in secondary school mathematics. Secondary School Mathematics Teaching, 3, 23-26.

Cao, H. (2011). Investigation of the current situation of mathematics teachers in extracurricular tutoring institutions for primary and secondary schools and ideas for improvement. Wuhan: Huazhong Normal University.

Fu, H.-X. (2014). Problems and reflections of the extracurricular tutoring market in primary and secondary schools. Beijing: Capital Normal University.

He, F. (2018). A study on the current situation of extracurricular tutoring in mathematics for elementary school students. Yangzhou: Yangzhou University.

He, X.-Q. (2013). A study on the reasons and advantages and disadvantages of primary school students' participation in extracurricular English tutoring. Wuhan: Huazhong Normal University.

Jiang, Y.-Z. (2014). A case study of secondary school students' participation in extracurricular mathematics tutoring classes. Chongqing: Chongqing Normal University.

Ke, S.-L. (2012). Research on the problems in the development of extracurricular tutoring institutions for primary and secondary school students in China. Hubei: Hubei University.

Liang, Y.-J., Liang, B., \& Luo, Z.-Q. (2018). Research on the current situation and trends of online education development of K12 extracurricular tutoring institutions in China. China Education Informatization, 11, $12-15$. 
Liu, S.-S., \& Yang, X.-D. (2015). A meta-analysis of the effect of extracurricular tutoring on students' academic performance. Educational Development Research, 35(22), 55-64.

Pei, C.-G., Song, N.-K., \& Liu, Q.-H. (2018). Empirical Analysis and Implications of Students' Participation in Extracurricular Tutoring in Compulsory Education. Chinese Journal of Education, 3, 43-48.

Shen, L. (2014). An analysis of the current situation of primary school students' participation in extracurricular tutoring in China and its advantages and disadvantages. China Out-of-School Education, 5, 32.

Shi, R.-Y. (2015). A study on extracurricular tutoring in mathematics for high school students. Suzhou: Soochow University.

Sun, H.-M. (2013). A study on the status of teachers in extra-curricular tutoring institutions in primary and secondary schools. Henan: Henan University.

Tang, P. (2015). Research on the development and functions of extracurricular tutoring institutions in primary and secondary schools. Chongqing: Southwest University.

Tang, X.-R. (2015). Research on the development of online education for extracurricular tutoring institutions. Kunming: Kunming University of Technology.

Wang, D. (2009). Psychological analysis of different roles in "paid tutoring". Jilin: Jilin University.

Wang, G.-Q. (2016). Analysis of extra-curricular tutoring in elementary school mathematics and its impact on academic performance and countermeasures. China Out-of-School Education, 31, 76-78.

Wen, Y.-J. (2013). Research on extracurricular tutoring in primary and secondary schools under the perspective of quality education. Wuhan: Zhongnan University for Nationalities.

Xia, A.-Q. (2019). Exploring the ways and methods of extracurricular tutoring in high school mathematics. Reading and Writing (Journal of Education and Teaching), 16(8), 62.

Zhou, Z.-C. (2015). Investigation study on the current situation of extra-curricular homework design and feedback in high school mathematics. Lanzhou: Northwest Normal University.

\section{Copyrights}

Copyright for this article is retained by the author(s), with first publication rights granted to the journal.

This is an open-access article distributed under the terms and conditions of the Creative Commons Attribution license (http://creativecommons.org/licenses/by/4.0/). 